\title{
Danazol enhances Fas-mediated apoptosis in human endometrial epithelial cells within normal physiology
}

\author{
TETSUJI TANAKA and NAOHIKO UMESAKI \\ Department of Obstetrics and Gynecology, Wakayama Medical University, \\ 811-1 Kimi-idera, Wakayama 641-0012, Japan
}

Received August 29, 2008; Accepted October 21, 2008

DOI: 10.3892/ijmm_00000122

\begin{abstract}
Local danazol therapy reduces the signs and symptoms of endometriosis without inhibition of regular ovulation and menstruation and without atrophic changes to the endometrium or vaginal wall. It has been suggested that danazol has possible non-cytotoxic direct actions on eutopic endometrial cells and endometriotic cells. We have investigated the direct effects of danazol on a human endometrial epithelial cell line, HHUA, which is believed to retain many normal intracellular signaling pathways. A thoroughly dissolved solution of danazol enhanced Fasmediated apoptosis in HHUA cells without inhibiting cell proliferation. Semi-quantitative flow cytometric analysis revealed that danazol did not enhance cell surface expression of Fas antigens. The enhancement of Fas-mediated apoptosis by endometrial cytokines such as EGF, IL-1ß and interferon- $\gamma$ was not additively enhanced by danazol; nor did danazol enhance growth suppression by anticancer drugs such as paclitaxel, carboplatin and 5-fluorouracil. Moreover, danazol did not enhance the irradiation-induced cell growth suppression of radiation-sensitive human cervical squamous cancer ME180 cells. These results indicate that danazol may regulate endometrial epithelial cell proliferation and apoptosis within normal physiology.
\end{abstract}

\section{Introduction}

Proliferation of endometriotic cells is known to be regulated by ovarian estrogen: patients with active endometriotic lesions are young women with regular menstruation and regression of endometriotic lesions is induced by gonadotropin-releasing hormone agonist (GnRHa) therapy or bilateral oophorectomy. Danazol, an anti-endometriosis progestin-like agent $(1,2)$, has been applied clinically for endometriosis and adenomyosis for several decades, although its mechanism has remained unknown. The standard oral dose of danazol for endometriotic

Correspondence to: Dr Tetsuji Tanaka, Department of Obstetrics and Gynecology, Wakayama Medical University, 811-1 Kimi-idera, Wakayama 641-0012, Japan

E-mail: obgywmu@wakayama-med.ac.jp

Key words: danazol, endometriosis, apoptosis, Fas patients is $400-800 \mathrm{mg}$ per day, which inhibits production of ovarian estrogen and the luteinizing hormone surge from the pituitary gland and causes dysovulation and amenorrhea and acts as a progestin-like steroid hormone (3-11).

Although endometrial atrophy occurs when endometriotic patients receive a daily oral dose of 200-800 mg danazol (9), local administration of low-dose danazol, such as by vaginal suppository (12-15), cervical injection (16), or the intrauterine danazol ring $(12,17)$, can improve endometriotic signs and symptoms without disrupting menstruation. Local danazol therapy does not inhibit ovulation or the production of endogenous estrogen $(12,13,15)$. From these clinical results, certain direct actions of danazol on endometriotic tissues have been hypothesized, but the mechanism of this direct action has not been made clear. Understanding how local danazol therapy is pharmacologically effective for endometriosis might provide a clue to the actual cause or pathogenesis of endometriosis.

There have been several studies of the direct action of danazol on endometrial epithelial cells (18-22). The effects of danazol have been examined in the highly differentiated endometrial adenocarcinoma Ishikawa cell line (18), surgically excised endometrial carcinoma cells (19) and normal human endometrial cells (20-22). The investigators in all cases concluded that danazol works directly on the cell by inhibiting proliferation. However, this does not explain the observation that a small dose of intrauterine danazol affects endometriosis without disturbing menstruation and ovulation (12). If danazol directly inhibited endometrial cell growth, patients treated with a danazol-coated intrauterine contraceptive device would be expected to complain of amenorrhea due to atrophic endometrial cells or abnormal genital bleeding due to endometrial ulcer; no such complications have ever been reported. If danazol directly inhibited epithelial cell growth, anti-endometriotic therapies with a vaginal danazol suppository (12-15) or cervical injection of danazol suspension (16) would be expected to induce vaginal ulcer lesions and destructive changes in uterine cervix; such complications have never been reported. Serum estradiol levels of patients receiving local danazol therapy are within normal limits and the patients require contraception during the therapy because normal ovulation is not inhibited. These facts indicate that the mechanism of action of local danazol therapy cannot be explained by direct cell growth inhibition. Therefore, we find a distinct discrepancy between the reported clinical effects of local danazol therapy and the inhibitory effects of danazol on endometrial cell growth observed in vitro. 
In an attempt to clarify this clinical discrepancy, we previously reported our in vitro culture experiments using two kinds of human endometrial adenocarcinoma cell lines and purified normal human endometrial stromal cells (23). However, the thoroughly dissolved danazol solution did not suppress growth of human endometrial cells either in short- or long-term cultures. These results suggested that suppression of endometrial cell growth might not be a result of the direct action of danazol: danazol concentrations up to $500 \mathrm{ng} / \mathrm{ml}$ were tested. Danazol concentrations in serum and peritoneal fluid have been reported to be $<5 \mathrm{ng} / \mathrm{ml}$ in endometriotic patients who received danazol vaginal suppositories and whose endometriotic symptoms had improved without any apparent disturbance of endogenous estrogen production or ovulation $(12,13,15)$.

When danazol has been clinically applied to patients with functional uterine bleeding (24) or endometrial hyperplasia lesions (25-31), danazol may act on endometrial lesions by inhibiting endogenous estrogen and by progestin-like functions. However, during local danazol therapy it seems likely that unknown direct actions of danazol regulate endometrial cell growth locally and directly. In this study, we have investigated the direct effects of danazol on human endometrial epithelial cells using the human endometrial epithelial cell line HHUA (32), which is believed to retain many normal intracellular signaling pathways (33).

\section{Materials and methods}

Preparation of danazol solution. Danazol solution was prepared according to the previously reported method (23). Danazol powder was kindly provided by Tokyo-Tanabe Pharmaceutical Co., Ltd. (Tokyo, Japan). When stock danazol solution $(10 \mathrm{mg} / \mathrm{ml}$ danazol in $99.5 \%$ ethanol) was diluted directly with culture medium and then added to the cell cultures, the culture media became white and turbid and insoluble danazol crystals were found in the cultures. In order to dissolve danazol thoroughly in the culture media, the stock danazol solution was diluted as follows: with ethanol to make $100 \mu \mathrm{g} / \mathrm{ml}$ danazol in ethanol, then with the culture medium to make $5 \mu \mathrm{g} / \mathrm{ml}$ danazol in $5 \%$ ethanol and finally stepwise with culture medium containing $5 \% \mathrm{v} / \mathrm{v}$ ethanol. One-ninth volume of the stepwise-diluted solution was added to each cell culture so that all cultures contained $0.5 \% \mathrm{v} / \mathrm{v}$ ethanol. Ethanol was also added to the control cell cultures at a final concentration of $0.5 \% \mathrm{v} / \mathrm{v}$. Using this dilution method, neither insoluble danazol crystals nor white turbidity was found in cell cultures.

Cell proliferation assay. The human endometrial epithelial cell line, HHUA, was obtained from Riken Cell Bank (Tsukuba, Japan). The cells were cultured in OPTI-MEM (Invitrogen, Carlsbad, CA, USA), fetal calf serum (FCS; 5\%; Equitech Bio Inc., Ingram, TX, USA), penicillin (PC; $100 \mathrm{U} / \mathrm{ml}$; Invitrogen) and streptomycin (SM; $100 \mu \mathrm{g} / \mathrm{ml}$; Invitrogen). The HHUA cell line was selected for this study because it expresses high levels of functional Fas antigen (33) as well as functional estrogen and progesterone receptors (32), as in normal human endometrial epithelium. The cells also form glandular luminal structures in collagen gel cultures, similar to the structures formed by normal glandular epithelial cells (34). Analysis of 20 HHUA cells indicated a normal 46XX karyotype (data not shown). Based on these characteristics, HHUA cells are considered to retain many of the intracellular signaling pathways found in normal endometrial epithelial cells.

The effects of danazol on cell proliferation were assayed by cell proliferation assay kit (Dojin, Tokyo, Japan). On day 1, HHUA cells in the log phase were detached using $0.25 \%$ trypsin/1 mM EDTA (Invitrogen) and cultured overnight in 96-well culture plates (5000 cells/well) containing OPTI$\mathrm{MEM} / 5 \% \mathrm{FCS} / \mathrm{PC} / \mathrm{SM}$. On day 2, various concentrations of danazol (final concentration $0-500 \mathrm{ng} / \mathrm{ml}$ in $0.5 \% \mathrm{v} / \mathrm{v}$ ethanol) were added to the cells. On day 4 , cells were counted.

Cell viability assay. Cell viability was assayed using the cell proliferation assay kit. The stimulatory effects of murine anti-human Fas IgM (clone CH-11; MBL, Nagoya, Japan) or anticancer drugs on the growth of HHUA cells were determined as follows: On day 1, HHUA cells in the log phase were detached using $0.25 \%$ trypsin/ $1 \mathrm{mM}$ EDTA (Invitrogen) and cultured overnight in 96-well culture plates (5000 cells/ well) containing OPTI-MEM/5\% FCS/PC/SM. On day 2, various concentrations of anti-Fas IgM or an anticancer drug were added to the cells. On day 4, viable cells were counted with the kit.

The effects of danazol on cell growth inhibition by anti-Fas IgM or an anticancer drug were examined as follows: On day 2, danazol solution (final concentration $50 \mathrm{ng} / \mathrm{ml}$ in $0.5 \%$ $\mathrm{v} / \mathrm{v}$ ethanol) was added to the cells, and then, on day 3 , the cells were incubated with stepwise-diluted anti-Fas IgM or an anticancer drug. On day 5, viable cells were counted using the kit. The three anticancer drugs used were paclitaxel (courtesy of Bristol-Myers Squibb Japan, Tokyo, Japan), 5-fluorouracil (5-FU; courtesy of Kyowa-Hokko Co., Tokyo, Japan) and carboplatin (CBDCA; courtesy of Nihon-Kayaku Co., Tokyo, Japan).

To examine cytokine effects on Fas-mediated growth suppression of HHUA cells, one of three cytokines [recombinant human epidermal growth factor (EGF; Update Biotech. Inc., New York, NY, USA), recombinant human IL-1B (courtesy of Otsuka Pharmaceuticals, Tokushima, Japan) or recombinant human interferon- $\gamma$ (IFN $\gamma$; Invitrogen)], was added to the cells on day 2. On day 3, stepwise-diluted anti-Fas IgM was added. Final cytokine concentrations were $50 \mathrm{ng} / \mathrm{ml}$ recombinant human EGF, $1 \mathrm{ng} / \mathrm{ml}$ recombinant human IL-1ß and $200 \mathrm{U} / \mathrm{ml}$ recombinant human IFN $\gamma$. On day 5 , viable cells were counted using the cell proliferation assay kit. To examine the combination effects of danazol and cytokines on Fas-mediated apoptosis, on day 2, danazol $(50 \mathrm{ng} / \mathrm{ml})$ was added to the HHUA cells $1 \mathrm{~h}$ before the cytokines were added. On day 3, anti-Fas IgM was added and on day 5 viable cells were counted.

All experiments were performed thee times. Graphical data were plotted as mean \pm SD and data were compared by t-test $(n=6)$ and/or one-way ANOVA. Values of $p<0.05$ were considered to indicate statistically significant differences.

Irradiation sensitivity assay. A radiosensitive human squamous cell carcinoma cell line, ME180 (35), was used in the 


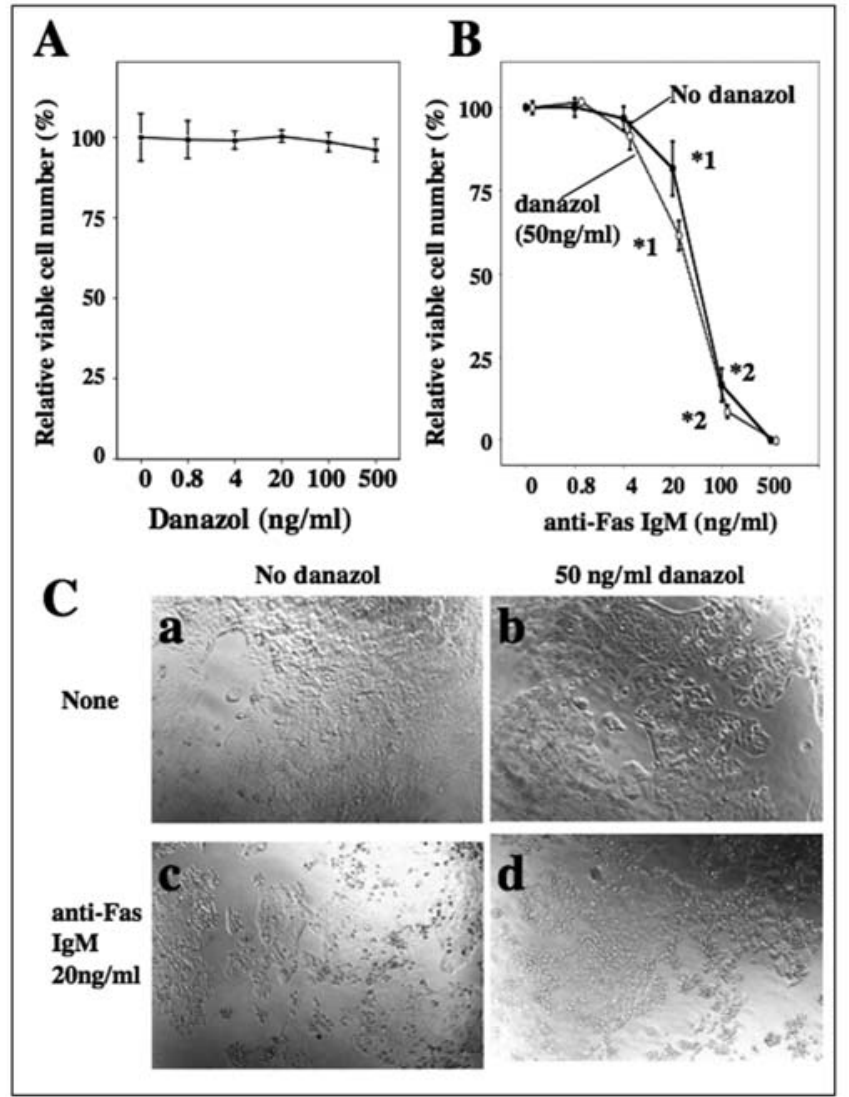

Figure 1. Danazol enhances Fas-mediated growth suppression of HHUA cells. (A) Dose-dependent effects of danazol on the cell proliferation of HHUA cells. (B) Effects of danazol on Fas-mediated growth suppression of HHUA cells. (C) Microscopic views of cultured HHUA cells treated with danazol $(50 \mathrm{ng} / \mathrm{ml})$ and/or anti-Fas $\operatorname{IgM}(20 \mathrm{ng} / \mathrm{ml})$.

irradiation sensitivity assay. On day 1, ME180 cells in the log phase were detached using $0.25 \%$ trypsin/ $1 \mathrm{mM}$ EDTA and cultured overnight in 96-well culture plates (5000 cells/well) containing OPTI-MEM/5\% FCS/PC/SM. On day 2, the cells were irradiated with various doses of $\gamma$-rays using an MBR 1520A irradiator (Hitachi-Medico, Tokyo, Japan) $1 \mathrm{~h}$ after various doses of danazol solution had been added to the cells. On day 4, viable cells were counted using the kit.

Semi-quantitative flow cytometry Confluently proliferated HHUA cells were incubated with danazol $(100 \mathrm{ng} / \mathrm{ml})$ for $24 \mathrm{~h}$ and then detached from tissue culture dishes using $3 \mathrm{mM}$ EDTA in phosphate-buffered saline (PBS) and stained according to the following procedure. Cells $\left(3 \times 10^{5}\right)$ were incubated with an excess of mouse anti-human Fas (CD95) monoclonal antibody (clone UB2; MBL) for $20 \mathrm{~min}$ at $4^{\circ} \mathrm{C}$ and then washed twice with washing buffer (PBS containing $2 \%$ FCS and $0.1 \% \mathrm{NaN}_{3}$ ). The cells were then reacted with FITC-conjugated goat anti-mouse $\operatorname{IgG}(\mathrm{H}+\mathrm{L})$ (Dako) as a secondary antibody for $20 \mathrm{~min}$ at $4^{\circ} \mathrm{C}$ and washed twice. Finally, the cells were suspended in $200 \mu$ l of washing buffer and analyzed using a FACSCalibur flow cytometer (Becton-Dickinson). HHUA cells treated with the secondary antibody alone were used as negative controls.

DNA fragmentation assay. HHUA cells in the log phase were detached with $0.25 \%$ trypsin/ $1 \mathrm{mM}$ EDTA and then cultured

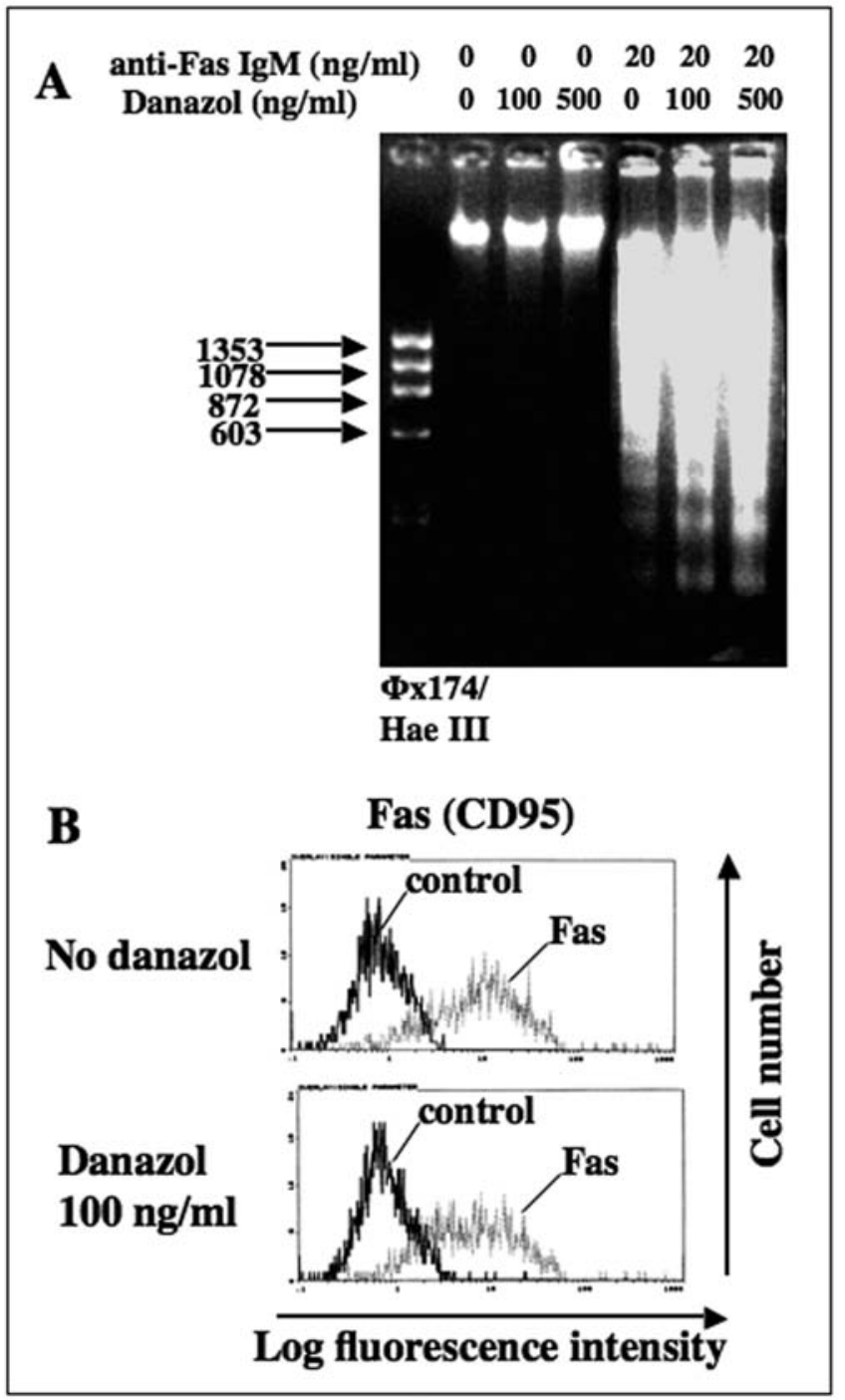

Figure 2. Danazol enhances Fas-mediated apoptosis without increased Fas expression. (A) DNA fragmentation assay of HHUA cells treated with danazol and anti-Fas IgM. Fas-mediated DNA fragmentation was increased in the cells treated with danazol. (B) Semi-quantitative flow cytometric assay of HHUA cells treated with $100 \mathrm{ng} / \mathrm{ml}$ danazol. Thick lines show negative controls and thin lines danazol-treated cells.

overnight in culture dishes $\left(3 \times 10^{6}\right.$ cells/dish) containing OPTI-MEM/5\% FCS/PC/SM. On day 3, $1 \mathrm{~h}$ after diluted danazol solutions (final concentration $0,100,500 \mathrm{ng} / \mathrm{ml}$ in $0.5 \% \mathrm{v} / \mathrm{v}$ ethanol) had been added to the cells, murine antihuman Fas IgM (clone CH-11) (final concentration $20 \mathrm{ng} / \mathrm{ml}$ ) was added. On day 4, genomic DNA was extracted from all cells, including the dead ones, using a SepaGene DNA extraction kit (Sankyo-Junyaku Co. Ltd., Tokyo, Japan) and treated with $100 \mu \mathrm{g} / \mathrm{ml}$ of RNase A (Sigma, St. Louis, MO, USA) in TE buffer (10 mM Tris, pH 8.0, 2 mM EDTA) for $90 \mathrm{~min}$ at $37^{\circ} \mathrm{C}$ to remove any contaminating RNA. Next, $20 \mu \mathrm{g}$ of the genomic DNA was electrophoresed in a $1.2 \%$ agarose gel at $50 \mathrm{~V}$ for $\sim 2 \mathrm{~h}$, stained with $5 \mu \mathrm{g} / \mathrm{ml}$ of ethidium bromide and visualized by UV fluorescence.

\section{Results}

Direct effects of danazol on Fas-mediated apoptosis in HHUA cells. When danazol was thoroughly dissolved in the culture 

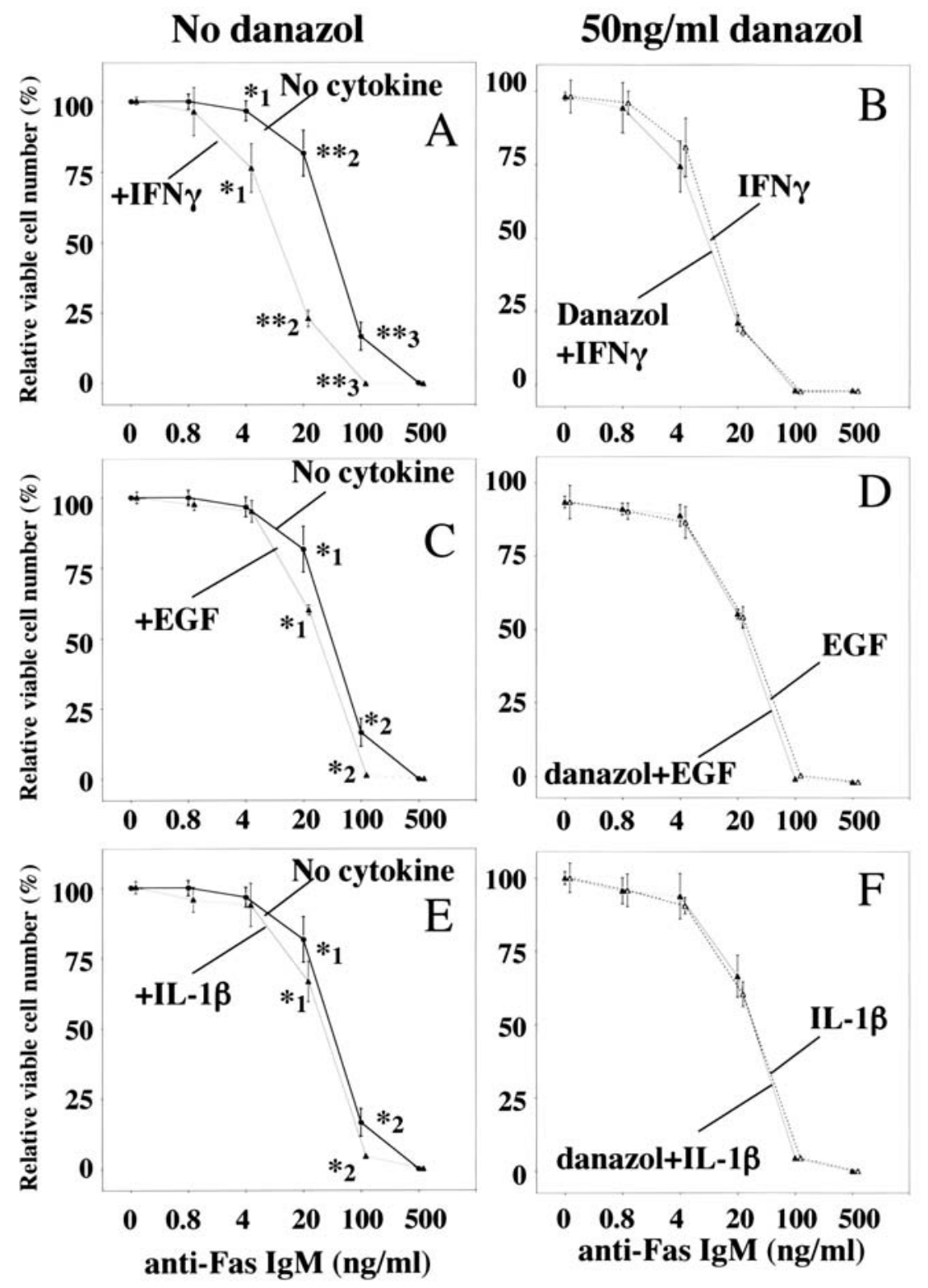

Figure 3. Combination effects of danazol and cytokines on Fas-mediated growth suppression of HHUA cells. (A, C and E) Cytokine effects on Fas-mediated growth suppression. Solid lines with closed circles indicate cells treated with anti-Fas IgM alone. Solid lines with closed triangles indicate cells treated with anti-Fas IgM and a cytokine. (B, D and F) Combination effects of danazol and cytokines on Fas-mediated growth suppression. Solid lines with closed triangles indicate cells treated with anti-Fas IgM and a cytokine. Dotted lines with open triangles indicate cells treated with anti-Fas IgM, a cytokine and danazol $(50 \mathrm{ng} / \mathrm{ml}) ;{ }^{*} \mathrm{p}<0.05,{ }^{* *} \mathrm{p}<0.01$.

media, it did not inhibit proliferation of HHUA cells (Fig. 1A). The cell growth inhibition stimulated in HHUA cells by antiFas IgM was significantly enhanced when $50 \mathrm{ng} / \mathrm{ml}$ of danazol, equivalent to the serum danazol concentration obtained during oral danazol therapy (600-800 mg/day), was added to the culture medium (Fig. 1B). Microscopically, HHUA cells treated with anti-Fas IgM and danazol showed more collapsed non-adherent cell debris than control cells treated with anti-Fas IgM alone (Fig. 1C). Further DNA fragmentation assay confirmed that DNA fragmentation in HHUA cells treated with anti-Fas IgM was enhanced by the addition of danazol (Fig. 2A).

Combination effects of danazol and cytokine on Fas-mediated apoptosis of HHUA cells. Semi-quantitative flow cytometric analysis were performed to make clear the mechanism of danazol's effect on Fas-mediated apoptosis. As shown in Fig. 2B, danazol treatment did not enhance cell-surface expression of the Fas antigen on HHUA cells, suggesting that danazol acts after Fas stimulation. Several endometrial cytokines such as EGF (36), IL-1ß (37), TGF-ß1 (38) and HGF (39) have been reported to enhance susceptibility to Fas-mediated apoptosis in HHUA cells without increased Fas expression; therefore, we examined the combination effects of danazol and an endometrial cytokine. Although EGF, IL-1ß and IFN $\gamma$ enhanced the Fas-mediated growth suppression (Fig. 3A, C and E), as reported before, combination with danazol did not show any additive effects (Fig. 3B, D and F).

Effects of danazol on anticancer drug-and irradiation-induced cell growth suppression. If danazol can enhance cancer cell death induced by anticancer drugs or irradiation as well as the 

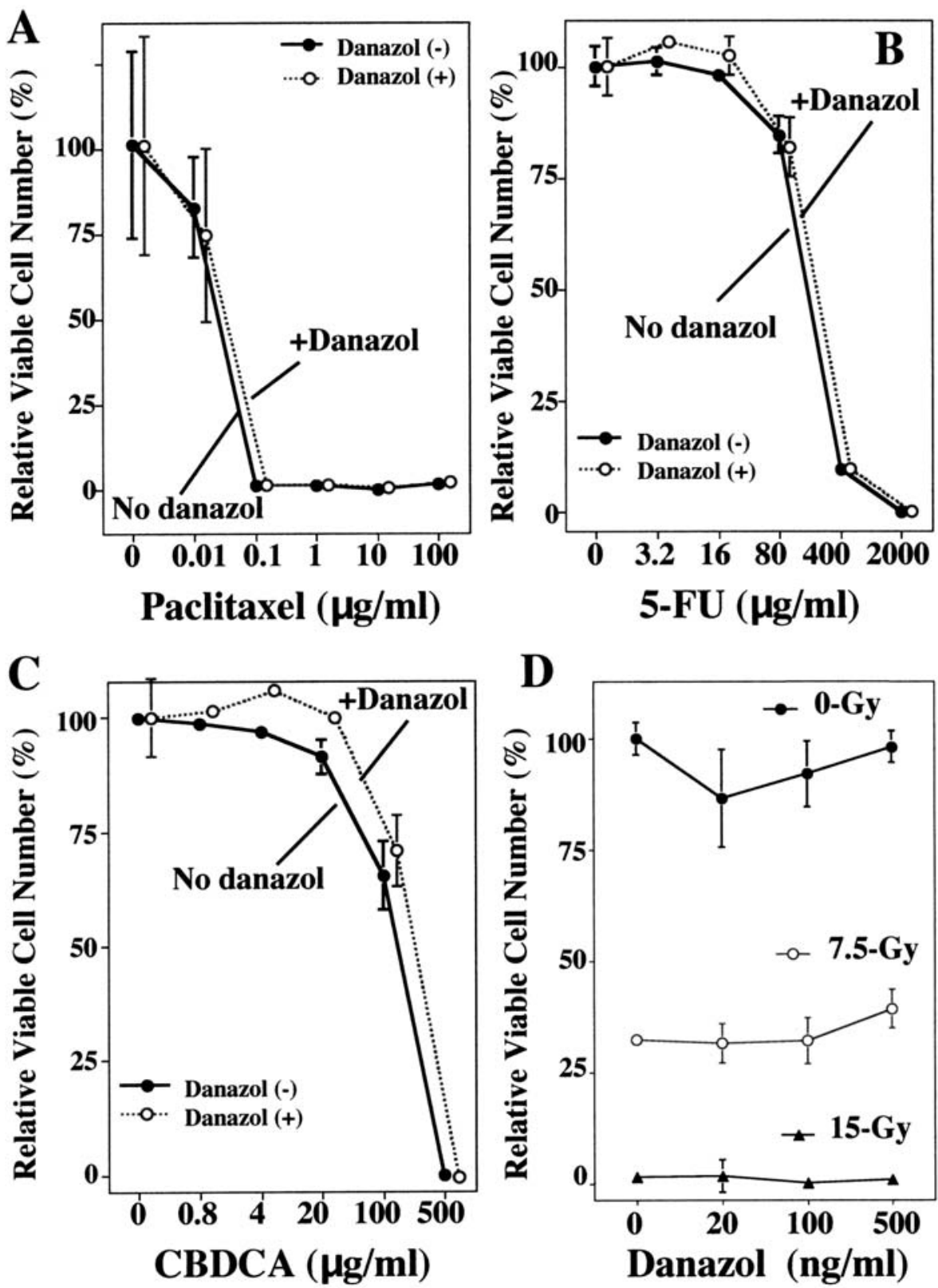

Figure 4. Danazol effects on the death of cells exposed to anticancer drugs or irradiation. (A, B and C) Danazol effects on anticancer-drug-induced deaths of HHUA cells. Solid lines with closed circles indicate HHUA cells treated with anticancer drug alone. Dotted lines with open circles indicate HHUA cells treated with anticancer drug and danazol (50 ng/ml). (D) Danazol effects on viability of irradiated ME180 cells.

Fas-mediated apoptosis in HHUA cells, it might be of use for cancer patients. Cell growth suppression of the HHUA cells by anticancer drugs such as paclitaxel, 5-FU and CBDCA was not enhanced by the addition of danazol (Fig. 4A-C). The effects on irradiation cell death were also examined using the human cervical squamous-cell carcinoma cell line ME180, which is very sensitive to irradiation (35). Addition of danazol did not have any effect on irradiation-induced cell growth suppression (Fig. 4D).

\section{Discussion}

Though danazol has been clinically applied to endometriotic and adenomyotic patients for $>20$ years, its mechanism has not been clarified. Local danazol therapy reduces the symptoms and signs of endometriosis without inhibiting endogenous estrogen production and ovulation. Moreover, patients need contraception during the therapy because it does not inhibit pregnancy. If danazol has a direct effect on endometriotic cells with normal serum estradiol levels, the effect may be a regulation of homeostasis within physiological limits. Here, we have shown that danazol enhances Fas-mediated intracellular signaling but does not affect cell proliferation. Moreover, this apoptosis-enhancing effect is mild and safe enough to regulate within physiological cytokine effects, indicating that danazol inhibits endometriosis safely.

Danazol is considered to enhance intracellular signaling after Fas stimulation because the enhancement of Fas-mediated apoptosis in HHUA was not accompanied by any increase in 
Fas expression. The same Fas-apoptosis-enhancing effects have already been reported (33) in HHUA cells treated with anti-Fas IgM and endometrial cytokines such as IL-1ß, TGFß1 and EGF and we have data indicating that IFN $\gamma$ strongly enhanced Fas-mediated apoptosis in HHUA cells without any increase of Fas expression on the cell surface (Tanaka T, unpublished data). Therefore, we examined whether danazol could enhance the Fas-mediated growth suppression of HHUA cells by endometrial cytokines such as EGF, IFN $\gamma$ or IL-1ß; unexpectedly, danazol did not show any enhancement, indicating that it might regulate Fas-mediated apoptosis in endometrial epithelial cells within effects of endometrial cytokines, that is, within normal physiology. The facts suggest that the effects of danazol on Fas-mediated apoptosis in the endometrial epithelium are as mild as physiological changes. This may explain why danazol reduces endometriotic lesions without any cytotoxic injuries in eutopic endometrial epithelium.

We have also investigated the possibility that danazol may safely enhance the effects of anticancer drugs or irradiation on cancer cells; interestingly, danazol did not show any enhancing effect. Taking together all results of this study and our previous study (23), one of the main mechanisms at work in the safe local danazol therapy is the regulation of endometrial epithelial proliferation and apoptosis within the physiological limits.

\section{Acknowledgements}

This study was supported in part by a Grant-in-Aid for Scientific Research from the Ministry of Education, Science, Sports and Culture of Japan. We would like to thank Tokyo-Tanabe Pharmaceutical Co. Ltd. for donating the danazol.

\section{References}

1. Wentz AC, Jones GS, Sapp KC and King TM: Progestational activity of danazol in the human female subject. Am J Obstet Gynecol 126: 378-384, 1976.

2. Kokko E, Jaenne O, Kauppila A, Roennberg L and Vihko R: Danazol has progesterone-like actions on the human endometrium. Acta Endocrinol 99: 588-593, 1982.

3. Potts GO, Beyler AL and Schane HP: Pituitary gonadotropin inhibitory activity of danazol. Fertil Steril 25: 367-372, 1974.

4. Wood GP: hormonal changes associated with danazol therapy. Obstet Gynecol 45: 302-304, 1975.

5. Andrews MC and Wentz AC: The effects of danazol on gonadotropins and steroid blood levels in normal and anovulatory women. Am J Obstet Gynecol 121: 817-828, 1975.

6. Barbieri RL: Danazol inhibits steroidgenesis. Fertil Steril 28: 809-813, 1977.

7. Dmowski WP: Endocrine properties and clinical application of danazol. Fertil Steril 31: 237-251, 1979.

8. Hirshowitz JS, Soler NG and Wortsman J: Sex steroid levels during treatment of endometriosis. Obstet Gynecol 54: 448-450, 1979.

9. Floyd WS: Danazol: Endocrine and endometrial effects. Int J Fertil 25: 75-80, 1980

10. Barbieri RL: Danazol inhibition of steroidgenesis in the human corpus luteum. Obstet Gynecol 57: 722-724, 1981.

11. Barbieri RL and Ryan KJ: Danazol: Endocrine pharmacology and therapeutic applications. Am J Obstet Gynecol 141: 453-463, 1981

12. Igarashi M: A new therapy for pelvic endometriosis and uterine adenomyosis: local effect of vaginal and intrauterine Danazol application. Asia-Oceania J Obstet Gynecol 16: 1-12, 1990.
13. Takeda Y, Yano J, Hukui K, et al: Danazol concentration in peritoneal fluid: A comparative study of oral danazol capsule therapy and vaginal danazol suppository therapy. J Jpn Soc Endometriosis 14: 216-221, 1993.

14. Samejima T, Ishimaru T, Masuzaki H, et al: Effects of danazol vaginal suppository onendometriosis. J Jpn Soc Endometriosis 14: 222-225, 1993

15. Ito K, Itani Y, Kurai N, Tamori C, et al: Danazol vaginal tablet: clinical effects and tissue concentration of danazol. J Jpn Soc Endometriosis 15: 202-204, 1994.

16. Takebayashi T, Fujino Y, Umesaki N and Ogita S: Danazol suspension injected into the uterine cervix of patients with adenomyosis and myoma. Preliminary study. Gynecol Obstet Invest 39: 207-211, 1995.

17. Igarashi M, Abe Y, Fukuda M, et al: Novel conservative medical therapy for uterine adenomyosis with a danazol-loaded intrauterine device. Fertil Steril 74: 412-413, 2000.

18. Terakawa N, Ikegami H, Shimizu I, et al: Growth inhibition by Danazol in a human endometrial cancer cell line with estrogenindependent progesterone receptors. J Steroid Biochem 28: 571-574, 1987.

19. Terakawa N, Ikegami H, Shimizu I, et al: Inhibitory effects of Danazol and medroxyprogesterone acetate on $\left[{ }^{3} \mathrm{H}\right]$ thymidine incorporation in human endometrial cancer cells. J Steroid Biochem 31: 131-135, 1988.

20. Taketani Y and Mizuno M: Direct actions of danazol on endometrium. Obstet Gynecol (Tokyo) 52: 89-91, 1985.

21. Rose GL, Dowsett M, Mudge JE, White JO and Jeffcoate SL: The inhibitory effects of danazol, danazol metabolites, gestrinone, and testosterone on the growth of human endometrial cells in vitro. Fertil Steril 49: 224-228, 1988.

22. Surrey ES and Halme J: Direct effects of medroxyprogesterone acetate, danazol, and leuprolide acetate on endometrial stromal cell proliferation in vitro. Fertil Steril 58: 273-278, 1992.

23. Tanaka T, Umesaki N, Chen H, Mizuno K and Ogita S: Danazol effects on human endometrial cells in vitro. Clin Exp Obstet Gynecol 26: 67-70, 1999.

24. Farquhar CM: Management of dysfunctional uterine bleeding. Drugs 44: 578-584, 1992.

25. Jasonni VM, Naldi S, La Marca L, et al: Preliminary report on postmenopausal endometrial hyperplasia treatment with Danazol: histological and endocrinological aspects. Cancer Detect Prev 9: 331-335, 1986.

26. Bulletti C, Jasonni VM, Tabanelli S, et al: Danazol reverses endometrial hyperplasia to normal endometrium. Acta Eur Fertil 18: 185-187, 1987.

27. Terakawa N, Inoue M, Shimizu I, et al: Preliminary report on the use of danazol in the treatment of endometrial adenomatous hyperplasia. Cancer 62: 2618-2621, 1988.

28. Soh E and Sato K: Clinical effects of danazol on endometrial hyperplasia in menopausal and postmenopausal women. Cancer 66: 983-988, 1990

29. Sedati A, Mariani L, Giovinazzi R, et al: The effectiveness of danazol therapy in postmenopausal women affected by endometrial hyperplasia. Clin Exp Obstet Gynecol 19: 161-165, 1992.

30. Mariani L, Sedati A, Giovinazzi R, Sindico R and Atlante G: Postmenopausal endometrial hyperplasia: role of danazol therapy. Int J Gynaecol Obstet 44: 155-159, 1994.

31. Tamaoka Y, Orikasa H, Sumi Y, et al: Direct effect of danazol on endometrial hyperplasia in adenomyotic women: treatment with danazol containing intrauterine device. Hum Cell 13: 127-133, 2000.

32. Ishiwata I, Ishiwata C, Soma M, Arai J and Ishikawa H: Establishment of human endometrial adenocarcinoma cell line containing estradiol-17ß and progesterone. Gynecol Oncol 17: 281-290, 1984.

33. Tanaka T and Umesaki N: Cytokine regulation of apoptotic susceptibility in a human endometrial epithelial cell line. J Reprod Immunol 47: 105-119, 2000.

34. Mikami M, Sakai K, Yoshiki J, et al: Differentiation of endometrial carcinoma cell lines cultured in type 1 collagen gel and significance of sulfate lipid. Acta Obstet Gynecol Jpn 48: S348, 1996.

35. Tanaka T, Bai T, Yukawa K and Umesaki N: Radiationinduced cell death is independent of the apoptotic signals mediated by death-associated protein kinase in human cervical squamous cell carcinoma cells. Oncol Rep 14: 949-955, 2005. 
36. Tanaka T, Mizuno K, Miyama M, et al: Enhanced Fas/CD95mediated apoptosis by epidermal growth factor in human endometrial epithelial cells. Eur J Obstet Gynecol Reprod Biol 86: 189-194, 1999.

37. Tanaka T, Umesaki N, Mizuno K, et al: Enhancement of apoptotic susceptibility by interleukin-1 in human endometrial epithelial cells. Gynecol Endocrinol 12: 315-319, 1998.

38. Tanaka T, Umesaki N, Mizuno K, et al: Enhancement of apoptotic susceptibility in human endometrial epithelial cell line HHUA by transforming growth factor- $\beta 1$. Horm Metab Res 30 : $61-65,1998$
39. Tanaka T, Mizuno K, Umesaki N and Ogita S: Suppressed apoptotic susceptibility in human endometrial epithelial cells pretreated with hepatocyte growth factor. Clin Exp Obstet Gynecol 25: 125-128, 1998. 